\title{
Economic-Financial Evaluation of Brazilian Companies With Open Capital in the Period 2011 to 2018
}

\author{
Emanuel Rodrigues de $\operatorname{Vargas}^{1}$, Clailton Ataídes de Freitas ${ }^{2}$ \& Daniel Arruda Coronel ${ }^{2}$ \\ ${ }^{1}$ Economics and Development, The Federal University of Santa Maria (UFSM), Rio Grande do Sul, Brazil \\ ${ }^{2}$ Department of Economics and International Relations, The Federal University of Santa Maria (UFSM), Rio Grande \\ do Sul, Brazil \\ Correspondence: Daniel Arruda Coronel, Department of Economics and International Relations, The Federal \\ University of Santa Maria (UFSM), Rio Grande do Sul, Brazil.
}

Received: December 19, 2020

Accepted: January 26, 2021

Online Published: April 5, 2021

doi:10.5430/ijba.v12n3p57

URL: https://doi.org/10.5430/ijba.v12n3p57

\begin{abstract}
The present research aimed to evaluate the economic and financial situation of Brazilian open capital companies between 2011 and 2018. Therefore, an artificial neural network (ANN) backpropagation algorithm was estimated, as well as a discriminant function, using a sample of 285 Brazilian companies with open capitals. As main results, the ANN algorithm was identified as the best method of this evaluation, which relates the company's situation with its most recent past, which proved to be more efficient in companies classification with profitable or loss situation, presenting $83,8 \%$ of assertiveness. Moreover, it was possible to identify that the discriminant analysis method did not present statistical significance in the evaluation of these companies. Finally, the important variables in the classification were general liquidity, net margin, debt composition, return on investment, turnover of the asset, physical production index.
\end{abstract}

Keywords: economic-financial analysis, artificial neural networks, discriminant analysis

\section{Introduction}

The competitive environment in which companies operate, having to make choices about uncertainties, leads them to search for innovation in order to continue, or even expand their market share. Innovations occur with new products launch or new production processes, but often they can also emerge, incrementally, in existing products and processes.

In order to remain profitable in long term, a company needs, in addition to constantly innovate, keep finances balanced. Responsible financial management allows the company to have its own resources to expand and modernize capital stock, train labor and have an efficient marketing structure, or even, for example to obtain credit, as pointed out by Guo and Luo (2017) in case of technological shock companies can lose money and would need temporary credits. Under these conditions, the company not only guarantees its survival in eventually adverse market shocks but also can take advantage of this adversity to expand its market participation, since crises, such as this deep global crisis caused by Covid19, can generate good investment opportunities.

The good financial condition of companies, in Brazil, becomes even more salutary, as the country is one of the worst worldwide in terms of business environment. According to the World Bank, based on the Doing Business Report (2018), Brazil ranked the 109th in the "Ease of Doing Business" index. The index is calculated based on the characteristics of each nation's market and seeks to identify the situation of business environments.

Still in that perspective, regarding the ease of paying taxes and contributions, the country ranks 184 th out of 190 countries surveyed, according to that report, it depicts a complex and heavy tax structure, which configures itself in an environment that undermines companies' competitiveness.

In view of the unfavorable picture of the economic environment in the country and in order to reduce losses of profitability and maximize the efficiency of business strategies, there is a growing need to use adequate and robust quantitative tools to assist decision made by executives. If detected in time, the consequences of possible unfavorable scenarios can be reversed or minimized, avoiding exposing companies to high level risks that can even lead them to possible bankruptcy. 
Several studies have sought to assess, based on economic and financial indicators, whether a given company can be classified as profitable or not. Among these studies, Chung et al. (2008) and Chen and Du (2009), who built neural networks as a model for predicting the financial health situation; respectively, of New Zealand industrial companies and Taiwanese companies listed on the financial markets of those countries. Teixeira et al. (2013) used the discriminant analysis method to classify the financial situation of 255 companies listed on BMF\&Bovespa. Aydin (2015) evaluated the use of artificial neural networks (ANN) in the identification of financial crises in the Turkish economy, with seven macroeconomic and financial indicators, between the years 1990 and 2014. Azayite and Achchab (2018) used the neural network method to build tooling as an alarm to predict a company bankruptcy situation.

Despite this, no studies were reported that sought to study the financial health of open capital companies in Brazil, from 2011 to 2018, with the concomitant application of ANN method and discriminant analysis (DA). With this, the present research sought to contribute to the academic discussion about the empirical application of statistical models, which can help executives in business decision making, especially at times when the economy enters into recession and depression. Furthermore, the present study aimed to contribute, mainly, in the sense of seeing if the proposed models are efficient tools to minimize uncertainties inherent to the economic environment.

This problem can be outlined as follows: Are the ANN model and the DA efficient tools in classifying, from a set of economic and financial indicators, the open capital companies in profitable or not, thus, serving as references in decision making by business managers

In order to answer the research problem, the general objective of this study was to assess the economic and financial situation of open capital companies, between 2011 and 2018, aiming to classify them into two groups (profitable and non-profitable) according to their financial indexes and economic variables, based on the use of ANN and DA.

The period chosen was characterized by a strong fluctuation in economic activity in Brazil, with a consequence on the solvency capacity of companies. In addition, this period matches with the last standardization published in the Accounting Technical Pronouncements of the Accounting Pronouncements Committee, related to the structure of balance sheets and financial statements.

The present research was structured in five sections, the first section is composed of this introduction; in section 2, some studies are presented that involve the economic and financial evaluation of open capital companies listed on stock exchanges; in section 3, the methodological procedures used are presented, in which the characterization of the sample is presented, the variables and the methods used to conduct the research in question, which consisted of a ANN preparation and a discriminating function; in section 4, results are analyzed and discussed and, finally, in section 5, the study is concluded.

\section{Literature References}

Mathematical, statistical and econometric models of artificial neural networks (ANN), among others, which are always evolving, contribute to the understanding of the phenomena relevant to economic agents choices under an environment of economic uncertainty. In the literature, several models used to identify the financial health of the company appear, which allow the construction of optimized decision making, minimizing risks and increasing investments returns. In this section, the most recent studies are presented, which use quantitative methods in risk evaluation of corporate insolvency.

Odom and Sharda (1990) used the DA and ANN methods to estimate the classification of 129 companies between 1975 and 1982, collected in Moody's Industrial Manuals, of which 65 were bankrupt. In addition, it compares the prediction of each method. Two samples were generated, one for training and testing with 74 companies and another for validation with 55 companies. For training, three proportions were made between bankrupt and non-bankrupt companies, respectively, 50\% / 50\%, 80\% / 20\% and 90\% / 10\%. For the validation sample, the 3 proportions showed respectively, with DA $74 \%, 78 \%$ and $69 \%$, with ANN $81 \%, 78 \%$ and $81 \%$. Thus, they concluded that the use of ANN for prediction shows better results than DA.

Chung et al. (2008) used the DA and ANN method to estimate and compare the ability to predict the financial situation of New Zealand industries between 2004 and 2017. To do so, they used financial data on leverage, profitability, turnover, liquidity and structure companies, collected on their balance sheets. As main results, they reported that the model built from the neural network is more complete and has a more assertive process for forecasting companies' insolvency. The discriminant analysis had a classification of $62 \%$ of assertiveness, furthermore it violated the assumption of normality for independent variables.

Chen and Du (2009) used the ANN model and factor analysis to build prediction models. They consisted of a sample 
of sixty-eight companies listed on the Taiwan Stock Exchange. In the study, thirty-seven financial and non-financial indexes were used. As main results, they indicated that the use of ANN has a high degree of precision power in predicting the assessment of companies' financial situation, vis-à-vis the factor analysis method.

Yildirim et al. (2011), using ANN, predicted, between 2000 and 2010, the monthly stock yield of fourteen companies listed on the Istanbul Stock Exchange and linked to the sectors of production of corrugated cardboard and other types of paper. The gold price, volume trading exchange, average purchase and sale of the exchange rate and monthly deposit were used as indicators. Finally, they reported that ANN was able to adequately predict, with $95 \%$ of correct answers, the income of the sampled companies

Teixeira et al. (2013) aimed to use the DA method in the estimation of functions to discriminate companies between profitable, intermediary and non-profitable companies, between 2009 and 2011. Variables used were liquidity (general, current and dry), turnover asset, assets return, net margin, equity return, indebtedness, debt composition and fixed assets. In all, the sample consisted of 255 companies listed on the BMF\&FBOVESPA. The authors constructed two discriminating functions and were able to identify that the indicators used and the functions constructed have high predictive power, verifying that $61.8 \%$ of the companies were classified correctly, and, when considering the average in the period, this percentage increased to $82.8 \%$.

Aydin et al. (2015) built an alert system, using ANN, so that it was possible to predict economic and financial crises in the Turkish economy, based on seven indicators, namely: US dollar, gold price, Istanbul Stock Exchange index, price index, money supply, domestic debt stock, and a index composed of economic indicators, between 1990 and 2014. The author, when presenting the real historical series compared to those predicted, identified that ANN has high predictive financial crises.

Björklund and Uhlin (2017) aimed to develop ANN to identify the time of assets return. Using a historical series of financial indicators, such as exchange rate, index of different assets such as stocks and commodities, indicated that in the ANN model there is no significant improvement in relation to the portfolio optimization, which is a method of choosing an investment portfolio.

Azayite and Achchab (2018) used a sample of 690 companies to build, using ANN, an alarm as a tool for predicting the risk of insolvency of companies in the service and commerce sectors of Morocco between 2010-2013. Thus, using information from the financial statements, not specified in the research, they highlighted that the ANN is valid as an alarm tool for a possible situation of insolvency risk. The authors indicated that there is approximately $85 \%$ accuracy in predicting the solvency capacity of companies with ANN use.

Prado et al. (2020) used ANN to estimate two solvency prediction models for 100 companies in the commercial sector in 2003, with 68 companies for training and 32 for validation. The first model defined 6 variables with 96.9\% of accuracy level while the second model has added 2 variables with $100 \%$ of accurancy discussed in the literature. The variable capital structure index presented, importance of $100 \%$ for the first model and $98.9 \%$ for the second. The profitability index was observer as another important variable for the two models. Then, they conclude that ANN has a high degree of prediction and relevance to evaluate the characteristics of the financial statements.

\section{Methodology}

\subsection{Theoretical Aspects of Artificial Neural Networks (Note 1)}

According to Mingoti (2017), ANN is applied in the estimation of time series, in cluster analysis, among others. This means that ANN is characterized as an information processor and that, from knowledge accumulation, it becomes available to define behavior patterns, using two aspects similar to the brain: (i) knowledge comes up through the process of learning existing in the network and, (ii) connection between neurons, considered as synaptic weight, has a determined capacity to acquire and store knowledge. Thus, the ANN is constituted from a learning process, which is called a learning algorithm and has the benefit of generalizing outputs about a certain phenomenon through learning, with network input training.

Corroborating, Braga, Carvalho and Ludermir (2000) argued that the ANN is made up of units that process in a simple way (nodes), calculating certain mathematical functions, and its functioning is based on a physical structure similar to that generated by the human brain nature.

It should be noted that ANNs have certain characteristics, namely: they are constituted in a non-linear way; they need to map the data from the input to the output, so that, after training, it is possible to make adjustments to the weights that make up the network and, thus, replicate them to other observations, if applicable; have the ability to adapt according to the environment to understand the characteristics of the analyzed phenomenon; have the ability to find 
patterns, to define which pattern adapts improves certain situations and what is the degree of confidence to perform a classification; have neurons that are activated by information in the network, but are also affected by other neurons belonging to it. The information that tries to explain a given phenomenon is used by the network to identify a pattern about it; it is able to tolerate failures, but it can deteriorate its performance and operability when there is a change in the conditions in which the information is presented; once the network is deployed in an integrated system, it is possible to perform tasks and identify extremely complex patterns; since they are universal, a given ANN can contribute and receive contributions from other neural networks, both in terms of building algorithms and theoretically; they arose from mimetic attempts in the neurobiological process, so they can be applied in the scientific development of neurobiology and, also, in solving problems in other areas of knowledge.

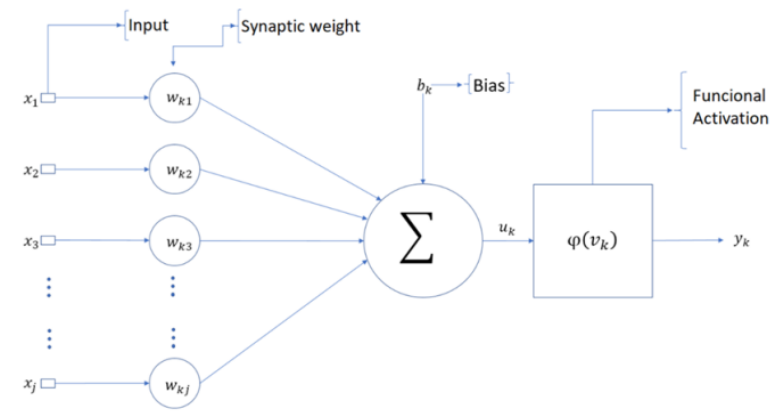

Figure 1. The general functioning of the ANN

Source: Author elaboration adapted fom Haykin (2001)

The basis for the constitution of ANN is the existence of neurons, shown in Figure 1. The neural network model can be described mathematically as follows:

$$
u_{k}=\sum_{j=1}^{k} \quad w_{k j} x_{j}
$$

Where: $u_{k}$ is the result given by the sum between the synaptic weights of neurons with each of the inputs, being $u_{k}$ just a linear combination of the weighting of each weight with $w_{k j}$ being the respective input of $x_{j}$.

According to Braga, Carvalho and Ludermir (2000), the sum of the weights of each neuron, or the weights of the nodes (connections) are given in the same way, which are then submitted to the activation function:

$$
\sum_{i=1}^{n} \quad w_{i} x_{i}
$$

Where: $n$ is the number of neurons considered, $w_{i}$ is the weight of each entry for each layer. With just one layer and one neuron, and $x_{i}$ becomes the value of each entry.

Finally, the output, or result, is given after the application of the activation function with bias influence, conceptually understood as a systematic error, being this process specified as:

$$
\begin{gathered}
y_{k}=\varphi\left(v_{k}\right) \\
y_{k}=\varphi\left(u_{k}+b_{k}\right)
\end{gathered}
$$

being, $v_{k}$ the sum of the weights by the respective input values $\left(u_{k}\right)$ with the values of the bias $\left(b_{k}\right)$, which can increase or decrease when entering the activation function; that is, it is a parameter external to the neuron $k ; \varphi$ is the activation function itself that will generate the output value, which can be 0 or 1 , if the function is a threshold function.

The activation function can be represented by: (i) a threshold (Note 2) function, in which the result of greater than or equal to 0 will cause an output equal to 1 , or 0 when the opposite occurs; (ii) a sigmoid function given as follows:

$$
\frac{1}{(1+\exp (-a v))}
$$

Formally, the ANN can have more than one neuron and with other layers, being characterized with multiple layers, as shown in Figure 2: 


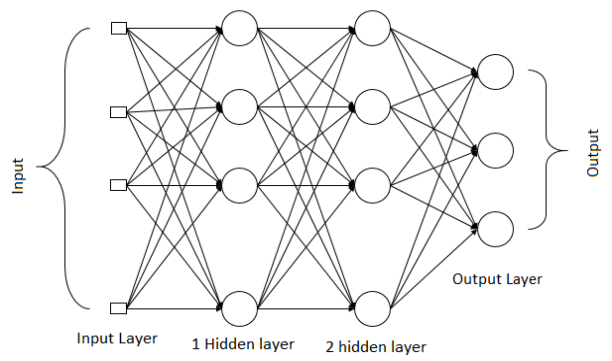

Figure 2. Perceptron Graph with two hidden layers

Source: Adapted from Haykin (2001)

The algorithm learning used in the ANN is intrinsically related to the form of learning presented by the neural network, and can be supervised or not supervised. As the algorithm used in the present study requires supervision, which is necessary for the scientific understanding of the financial solvency process of Brazilian companies, the algorithm with learning supervision is used. More specifically, a logistical function is given by:

$$
y_{j}=\frac{1}{\left(1+\exp \left(-v_{j}\right)\right)}
$$

For Braga, Carvalho and Ludermir (2000), supervised learning requires that the training carried out should be reviewed in case of a change from a situation different from the original, requiring the construction of a new learning strategy. According to the authors, the best known algorithm is backpropagation, which learns from the use of input and output to correct the output error, being considered an algorithm of the multilayer perceptron type (perceptron multilayer neural network).

The backpropagation algorithm is also known as error backpropagation, which is a perceptron multilayer network with the following characteristics: (i) each neuron has an activation function with a nonlinearity characteristic, which is given by a logistic function; (ii) as the network has other hidden layers, these are used to understand the phenomenon in its complexity; (iii) the network has a high degree of connection through synapses. It is worth noting that, if there is a need to change any of the connections, the synapses and their respective weights are also changed. According to Riedmiller and Braun (1993), the backpropagation algorithm of the neuralnet-package has the function of performing network application in order to reduce the error in calculating the output value

The backpropagation algorithm error is defined as a technique that efficiently calculates the partial derivatives of the neural network in order to adjust the weights of the network in relation to the input vector in the network by means of error return, minimizing the output vector and reducing the difference between the output and input.

The error signal at the neuron output $\mathrm{j}$ is already defined by:

$$
e_{j}(n)=d_{j}(n)-y_{j}(n)
$$

Where: $e_{j}(n)$ is the error signal of neuron $j ; d_{j}(n)$ is the desired response to neuron $j$ and $y_{j}(n)$ is the output signal from neuron $j$;

From Equation (7), it is possible to calculate the instantaneous value of the total error energy and the average error energy, which are defined as a function of free parameters (synaptic weights and bias), which are formally defined from the instantaneous value of the error energy. The error energy $(E)$ has an instantaneous value (square error) defined as:

$$
E=\frac{1}{2} e_{j}^{2}(n)
$$

The total error energy $[E(n)]$ is found by formally adding the squares of errors calculated according to Equation (8):

$$
E(n)=\frac{1}{2} \sum_{j \in C} \quad e_{j}^{2}(n)
$$

Where: $C$ is the set that contemplates the output neurons.

The average energy value is represented as a cost function of the network's learning process, calculated as follows:

$$
E_{\text {med }}=\frac{1}{N} \sum_{n=1}^{N} \quad E(n)
$$


Where, $E_{\text {med }}$ is the average of $E(n)$ considering all values of $N$, where $N$ is the number of observations used for training.

The input signal in the activation function is obtained from the weighted sum of the synaptic inputs with the bias, and this sum is called the local induced field, being defined as follows:

$$
v_{j}(n)=\sum_{i=0}^{m} \quad w_{j i}(n) y_{i}(n)
$$

$v_{j}(n)$ is the weighted sum of the entries with the bias (local induced field); $w_{j i}(n)$ is the synaptic weight of neuron $j$ to neuron $i$.

Thus, the output of the neuron $j$ is defined by:

$$
y_{j}(n)=\varphi_{j}\left[v_{j}(n)\right]
$$

where, $\varphi_{j}(n)$ is defined as the activation function, $n$ refers to the $\mathrm{n}^{\text {th }}$ standard of training on the network.

In this algorithm, the correction of synaptic weights is proportional to that derived from Equation (9) in relation to synaptic weights. Thus:

$$
\frac{\partial E(n)}{\partial w_{j i}(n)}=\frac{\partial E(n)}{\partial e_{j}(n)} * \frac{\partial e_{j}(n)}{\partial y_{j}(n)} * \frac{\partial y_{j}(n)}{\partial v_{j}(n)} * \frac{\partial v_{j}(n)}{\partial w_{j i}(n)}
$$

The partial derivative $\partial E(n) / \partial w_{j i}(n)$ is considered a factor that represents the sensitivity in determining the search for synaptic weights.

Differentiating $E(n)$ regarding $e_{j}(n)$ :

$$
\partial E(n) / \partial e_{j}(n)=e_{j}(n)
$$

Differentiating $e_{j}(n)=d_{j}(n)-y_{j}(n)$ regarding $y_{j}(n)$ :

Differentiating $y_{j}(n)=\varphi_{j}\left(v_{j}(n)\right)$ regarding $v_{j}(n)$ :

$$
\partial e_{j}(n) / \partial y_{j}(n)=-1
$$

$$
\partial y_{j}(n) / \partial v_{j}(n)=\varphi_{j}^{\prime}\left(v_{j}(n)\right)
$$

Differentiating $v_{j}(n)=\sum_{i=0}^{m} \quad w_{j i}(n) y_{i}(n)$ regarding $w_{j i}(n)$

$$
\partial v_{j}(n) / \partial w_{j i}(n)=y_{i}(n)
$$

Using all the differentiations specified in Equations (14) to (17), the following relationship is reached:

$$
\partial E(n) / \partial w_{j i}(n)=-e_{j}(n) \varphi_{j}^{\prime}\left(v_{j}(n)\right) y_{i}(n)
$$

Considering that the delta rule is defined as the search for the direction that modifies the weight to reduce the total error energy, the rule is defined as follows

$$
\Delta w_{j i}(n)=-\eta \partial E(n) / \partial w_{j i}(n)
$$

Where $\eta$ is the parameter called learning rate.

Using the two previous demonstrations, we found:

$$
\Delta w_{j i}(n)=\eta \delta_{j}(n) y_{i}(n)
$$

Where $\delta_{j}(n)$ is called the local gradient.

The local gradient indicates changes in weights, being defined as follows:

$$
\begin{gathered}
\delta_{j}(n)=-\partial E(n) / \partial v_{i}(n) \\
\delta_{j}(n)=-\partial E(n) / \partial e_{j}(n) * \partial e_{j}(n) / \partial y_{j}(n) * \partial y_{j}(n) / \partial v_{j}(n) \\
\delta_{j}(n)=e_{j}(n) \varphi_{j}^{\prime}\left(v_{j}(n)\right)
\end{gathered}
$$

An important factor for weights is the signal of the error, which, after verified, the neuron $J$ can be the output or a hidden node. In the first case, it appears that, after generating the error, the gradient is calculated to adjust the weights at the synapses and; for the second case, a second demonstration is necessary, with no specific response for the hidden neuron. Thus, it is necessary to define the error signal recursively, relative to the error of all the other neurons connected to it. For this, it is necessary to consider that:

$$
v_{j}(n)=\sum_{i=0}^{m} \quad w_{j i}(n) y_{i}(n)
$$

Which $m$ is the layer size, that is, the number of nodes. 
Whether the neuron is hidden, then it is necessary to redefine the local gradient as follows:

$$
\begin{gathered}
\delta_{j}(n)=-\partial E(n) / \partial y_{j}(n) * \partial y_{j}(n) / \partial v_{j}(n) \\
\delta_{j}(n)=-\partial E \frac{(n)}{\partial y_{j}(n)} * \varphi_{j}^{\prime}\left(v_{j}(n)\right)
\end{gathered}
$$

To find it is necessary to know that,

$$
E(n)=\frac{1}{2} \sum_{k \in C} \quad e_{k}^{2}(n)
$$

Where $\mathrm{k}$ is the output neuron, by differentiating Equation (27) regarding $y_{j}(n)$, we obtain:

$$
\partial E \frac{(n)}{\partial y_{j}(n)}=\sum_{k} \quad e_{k} \frac{\partial e_{k}(n)}{\partial y_{j}(n)}
$$

Considering the chain rule, it is possible to verify that:

$$
\partial E \frac{(n)}{\partial y_{j}(n)}=\sum_{k} \quad e_{k} \frac{\partial e_{k}(n)}{\partial v_{j}(n)} \frac{\partial v_{k}(n)}{\partial y_{j}(n)}
$$

Knowing that,

$$
e_{k}(n)=d_{k}(n)-y_{k}(n)
$$

That is,

$$
e_{k}(n)=d_{k}(n)-\varphi_{k}^{\prime}\left(v_{k}(n)\right)
$$

So,

$$
\frac{\partial e_{k}(n)}{\partial v_{j}(n)}=-\varphi_{k}^{\prime}\left(v_{k}(n)\right)
$$

In this second case, the induced local field is described as:

$$
v_{k}(n)=\sum_{j=0}^{m} \quad w_{k j}(n) y_{j}(n)
$$

By differentiating the local field, Equation (33) in relation to $y_{j}(n)$, we find:

$$
\frac{\partial v_{k}(n)}{\partial y_{j}(n)}=w_{k j}(n)
$$

where, $w_{k j}(n)$ are the synaptic weights of neurons in the hidden layer of the neural network.

Considering the above demonstration of the second case,

And

$$
\partial E \frac{(n)}{\partial y_{j}(n)}=-\sum_{k} \quad e_{k}(n) \varphi_{k}^{\prime}\left(v_{k}(n)\right) w_{k j}(n)
$$

$$
\partial E \frac{(n)}{\partial y_{j}(n)}=-\delta_{k}(n) w_{k j}(n)
$$

Thereby, the backpropagation formula is defined by calculating the local gradient of the neuron, which is hidden in the network, as shown below:

$$
\delta_{j}(n)=\varphi_{j}^{\prime}\left(v_{j}(n)\right) \sum_{k} \quad \delta_{k}(n) w_{k j}(n)
$$

The flow graph of the neuron $k$ connection to the hidden neuron $j$ is observed below. 

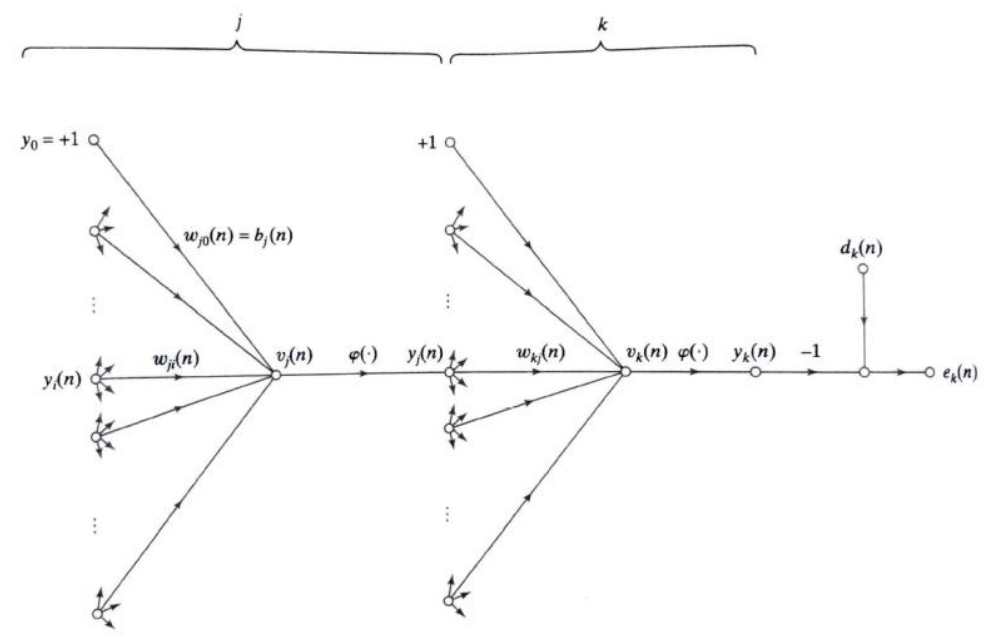

Figure 3. Signal flow with the hidden neuron $\mathrm{j}$

Source: Haykin (2001)

Since $\varphi_{j}^{\prime}\left(v_{j}(n)\right)$ is related to the activation function and the terms require $\delta_{k}(n)$ signals to the neuron $j$, moreover, it is the weights that represent the neurons connection.

Table 1. Backpropagation algorithm calculation

\begin{tabular}{lll}
\hline $1^{\circ}$ & $\begin{array}{l}\text { Correction of weights between neurons i } \\
\text { for j: Delta Rule }\end{array}$ & $w_{j i}(n)=\eta \delta_{j}(n) y_{i}(n)$ \\
\hline & $\begin{array}{l}\text { If the neuron is the network output then } \\
\text { the local gradient will be: }\end{array}$ & $\delta_{j}(n)=e_{j}(n) \varphi_{j}^{\prime}\left(v_{j}(n)\right)$ \\
\cline { 2 - 2 } $2^{\text {o }}$ & $\begin{array}{l}\text { If neuron } \mathrm{j} \text { is hidden, then the local } \\
\text { gradient will be: }\end{array}$ & $\delta_{j}(n)=\varphi_{j}^{\prime}\left(v_{j}(n)\right) \sum_{k} \delta_{k}(n) w_{k j}(n)$ \\
\hline
\end{tabular}

Source: Authors elaboration, based on Haykin (2001)

Briefly, the backpropagation algorithm has two fundamental relationships, as shown in Table 1.

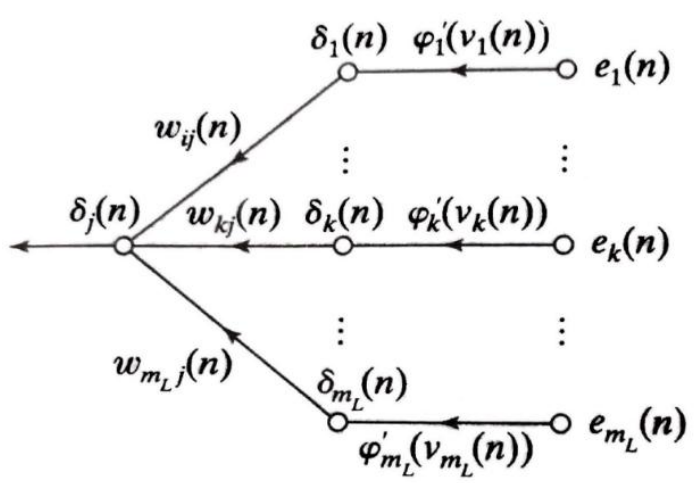

Figure 4. Adjustments flow in weights

Source: Haykin (2001) 
The image sketched in Figure 4 represents the flow of weight adjustments from the error to the $m_{l}$ neurons.

Figure 4 shows the calculation by the local gradient when the neuron $\mathrm{j}$ is hidden. Simply, it represents the information flow that changes the local gradient to adjust the total energy of the error in order to adjust the weights and, consequently, promote errors reduction.

According to Rumelhart et al. (1986), learning by error propagation in the neural network has the purpose of defining weights in which the output will be equal or very close to the desired, considering that there is an exact number of cases with where it is possible to verify the desired output and compare with the one produced. In accordance with the authors, even if the error backpropagation learning method cannot guarantee solutions for all types of problems, even so, in analysis application, results showed that there was a solution in practically all the studies carried out.

Finally, the ANN empirical model propose to analyze the financial health of Brazilian open companies is specified below, in which:

The first estimated model is built to verify the contemporary relationship between the variables and the economic and financial situation of the companies, that is, the relationship between the situation of 2018 and the economic indexes of 2018. Formally:

$$
\begin{array}{r}
\operatorname{Lucr}_{2018}=w_{k 1} L i q G_{2018}+w_{k 2} M L \operatorname{Lí}_{2018}+w_{k 3} \operatorname{CompEnd}_{2018}+w_{k 4} \text { EBITD }_{2018}+w_{k 5} R O I_{2018}+w_{k 6} R O E_{2018}+ \\
w_{k 7} P C T_{2018}+w_{k 8} G A_{2018}+w_{k 9} P F_{2018}+w_{k 10} V C_{2018}+w_{k 11} V S_{2018}+w_{k 12} T_{X P I B_{2018}}+b_{k}
\end{array}
$$

Where: $w_{k i}$ with $i=1,2, \cdots, 12$ represents the synaptic weights of input for each variable in the ANN.

The second model (Equation 39) deals with the relationship between the situation of 2018 and the variables of the immediately previous year, that is, it seeks to predict the situation of the company in 2018 regarding the independent variables of 2017. Thus, the model is defined formally as:

$$
\begin{array}{r}
\text { Lucr }_{2018}= \\
w_{k 1} L i q G_{2017}+w_{k 2} M L q_{2017}+w_{k 3} \text { CompEnd }_{2017}+w_{k 4} \text { EBITDA }_{2017}+w_{k 5} \text { ROI }_{2017}+w_{k 6} \text { ROE }_{2017}+ \\
w_{k 7} P C T_{2017}+w_{k 8} G A_{2017}+w_{k 9} P F_{2017}+w_{k 10} V C_{2017}+w_{k 11} V S_{2017}+w_{k 12} T X P I B_{2017}+b_{k}
\end{array}
$$

The third model generated in the neural network (Equation 40) is the relationship between 2018 and the history of each company from 2011 to 2017 , in formal terms:

$$
\begin{aligned}
& \text { Lucr }_{2018}=w_{k 1} \text { LiqG }_{2017}+w_{k 2} \text { MLíq }_{2017}+w_{k 3} \operatorname{CompEnd}_{2017}+w_{k 4} \text { EBITDA }_{2017}+w_{k 5} R_{0 I_{2017}}+w_{k 6} R O E_{2017}+ \\
& w_{k 7} P C T_{2017}+w_{k 8} G A_{2017}+w_{k 9} P F_{2017}+w_{k 10} V C_{2017}+w_{k 11} V S_{2017}+w_{k 12} T X P I B_{2017}+w_{k 13} L_{2016}+ \\
& w_{k 14} L_{2015}+w_{k 15} L_{2014}+w_{k 16} L_{2013}+w_{k 17} L_{2012}+w_{k 18} L_{2011}+b_{k}
\end{aligned}
$$

Where: the discrepancy in the ( $L u c r$ ) on the ANN serve to incorporate the company's profitable history, which, in the present study, will be limited to 2011, and refers to the bias of the neural network.

The proposed models were also carried out by Teixeira et al. (2013), Chung et al. (2008), Chen and Du (2009) and Aydin et al. (2015), and, in the last model, only the variables from previous years were added as an analysis proposal.

In order to verify the relevance of each variable in the ANN model, the method of Olden and Jackson (2020) was used to identify the level of importance of variables in patterns identification and classification in the learning process of the neural network. The method is defined as the sum of the product of the weights in the neural network linked to each variables, between the hidden layers with the input and output weights of each neurons. The calculation is performed by multiplying the input and output weight in each neurons, as follows:

$$
C=w_{k j} * w_{j i}
$$

Then, the result of the multiplication of each layer is added and it is divided from the first layer by all the terms of the following layers, which, according to the author, it also denominates the relative importance of each variable in the learning process of ANN.

To estimate Equations (38), (39) and (40), RStudio free software was used, with the neuralnet and NeuralNetTools packages.

\subsection{Describing, Specifying and Analyzing the Discriminant (Note 3)}

The discriminant analysis (DA) is used in addition to the ANN, mainly for the purpose of verifying the robustness of the estimates reached. According to Johnson et al. (2007), DA is a multivariate technique that seeks to separate the observations into groups, as well as to classify new observations in the pre-defined groups from a set of variables. 
Mingoti (2017) conceptualizes DA as a technique to classify observations, or objects of a sample or population. In order to be able to use it, it is necessary to have a classification or separation a priori, to later build a mathematical rule for discrimination based on the probability theory. The discriminant function can be defined generically as:

$$
Y=a^{\prime} X
$$

Where: $Y$ is a categorical variable; $a$ is a matrix of coefficients that determines the influence of each variable; $X$ represents the matrix of variables, the same ones used in ANN and described in table 2.

Based on Hair Jr (2009), the discriminant function can be described as follows, already making the necessary adaptations with the variables of the present study:

$$
\text { Lucr }_{j k}=a+W_{1} \text { LiqG }_{1 k}+W_{2} M L \text { Lí }_{k 2}+W_{3} \text { CompEnd }_{k 3}+W_{4} \operatorname{RentAtv}_{k 4}
$$

where, Lucr $_{j k}$ is the discriminating score Lucr of the discriminant function $j$ for the variable $k$, where Lucr is a binary variable, which is equal to 1 if there it is profitable and 0 otherwise; $a$ is the function intercept; $W_{i}$ with $i=1,2, \cdots, 13$ is the discriminating weight for the $\mathrm{i}^{\text {th }}$ independent variable; the other variables as described in board 2.

It is important to point out that Equation (42) is only a generic representation of the discriminant function most appropriate to the interests of the present study. However, the estimated discriminant functions are the same as those specified in Equations (38), (39) and (40).

One of the methods used to adjust the discriminant function is Fisher's, which identifies $a^{\prime}$ vectors so that groups can express the greatest difference between them, that is, the greatest difference between averages as well as the smallest variance. The biggest difference between the mean $(\Delta \mu)$ is defined by Johnson and Wichern (2007) as:

$$
\Delta \mu=\frac{\left(\underline{y}_{1}-\underline{y}_{2}\right)^{2}}{s_{y}^{2}}
$$

Where, $\underline{y}_{1}$ and $\underline{y}_{2}$ are, respectively, the average of two groups: 1 (profitable companies) and 2 (non-profitable) and $s_{y}^{2}=\frac{\sum_{j=1}^{n_{1}}\left(y_{1 j}-\underline{y}_{1}\right)^{2}+\sum_{j=1}^{n_{2}}\left(y_{2 j}-\underline{y}_{2}\right)^{2}}{n_{1}+n_{2}-2}$ is the joint variance of the two groups, being $y_{1 j}$ and $y_{2 j}$ the observations of the respective groups 1 and $2, n_{1}$ and $n_{2}$ represent the size of each of the two groups.

According to Mingoti (2017), one of the tests used to compare the population average is the F test, called the Hotelling (Note 4) test. The null hypothesis of this test is the equality between the means, but, if the test statistic is not statistically significant, the function must be reworked with new variables so that it is possible to discriminate groups.

Another test used to verify whether the variables that make up the discriminant function are statistically capable of distinguishing groups, equivalent to the $\mathrm{F}$ test, is the Box' $\mathrm{M}$, which has as a null hypothesis the equality between the variance and covariance matrices of the determined groups. Rejecting means that the linear discriminant function can be applied (Note 5).

\subsection{Data Source}

Data from publicly traded companies were collected at the sites: Brasil Bolsa Balcão (B3) (market value, volume of shares and number of companies) and Fundamentus () (Financial reports: Balance Sheet and Year Income Statement), among the years 2011 and 2018, that were active between 2017 and 2018.

The variables used to classify companies as solvent or non-solvent were selected based on the literature, especially in Matarazzo (2010), Marion (2012), Gitman (2010) and Assaf Neto (2018).

General liquidity $\left(\right.$ LiqG) is the reason $\frac{\text { Current assets }+ \text { Reacheable in long term }}{\text { Current liabilities }+ \text { Long term liabilities }}$. This indicator shows the ratio of current assets and long-term assets, for each $\mathrm{R} \$ 1.00$ of total debt.

The net margin (Mliq) is defined as: $\left(\frac{\text { Net profit }}{\text { Net sale }}\right) 100$. The indicator shows how much profit the company obtained for each R \$ 100.00 of sales made. 
The debt composition (CompEnd) is given by: $\left(\frac{\text { Current liabilities }}{\text { Third partycapital }}\right) 100$, and expresses the percentage relationship between the company's short-term obligations, with the total of obligations.

Earnings before interest, taxes, depreciation and amortization (EBITDA - Earnings before Interest, Taxes, Depreciation and Amortization) is calculated EBITDA = Gross profit-operational expenses + financial income. This indicator represents a potential for cash generation and to guarantee debt compliance.

The return on assets $(R O I)$ (Return On Investment) is defined as: $R O I=\left(\frac{\text { Net profit }}{\text { Assets }}\right) 100$. This represents the return on all investment made in the company

The return on equity ( $R O E$ ) (Return on Equity) is given by: $R O E=\left(\frac{\text { Net profit }}{\text { Net worth }}\right) 100$ and represents the return on investment made by the partners in the company.

The participation of third party capital $(P C T)$ is formalized by: $P C T=\left(\frac{\text { Third party capital }}{\text { Net worth }}\right) 100$. This indicator represents the relationship between third party capital and equity, that is, the greater the relationship between third party capital and equity, the lower the possibility of making financial decisions.

The turnover of the asset $(G A)$ represents how many times the sales revenue is higher than the investment, formally:

$\left(G A=\frac{\text { Net sale }}{\text { Assets }}\right)$

Besides these indicators, the following variables are also used as a way to assess the economic aspects of the company's financial situations:

a) Rate of change in the annual volume index of the respective economic sectors in which each company is inserted $\left(G A=\frac{\text { Net sale }}{\text { Assets }}\right)$. This index was used as indicators of cyclical activity in the market in which the company operates;

b) Annual sales volume index in retail trade (VC), which according to the Brazilian Institute of Geography and Statistics (IBGE, 2019), represents the volume of sales through retail trade, used as an indicator of market activity, specifically for sales to companies that are part of the retail trade activity;

c) Annual Industrial Physical Production Index (PF), which, according to IBGE (2019), is about measuring the production behavior of the extractive and processing industries and was used as an indicator of industrial market production for companies that are inserted in this market, more specifically than PIB, verifying the sector's annual production level;

d) Annual service volume index (VS), which, according to IBGE (2019), is an index that measures the level of services volume performed year by year, so this indicator was used, in this research, to the companies that are inserted in this type of activity as information of the market to which they belong.

These variables are based on the Monthly Industrial Survey (PF, TXPIB), Monthly Service Survey (VS), Monthly Trade Survey (VC), all available in IBGE (2019).

And, finally, a profit dummy variable $(L)$, which, when assuming a value of 1 , indicates that the company is profitable, and 0 , otherwise.

\section{Analysis and Discussion of Results}

\subsection{Estimates Using Artificial Neural Network (ANN) for Backpropagation Error}

The ANN error propagation, shown in Figure 5, uses logistics as an activation function. In order to reduce the estimate errors, ten repetitions of training are performed to adjust the neurons weights. 


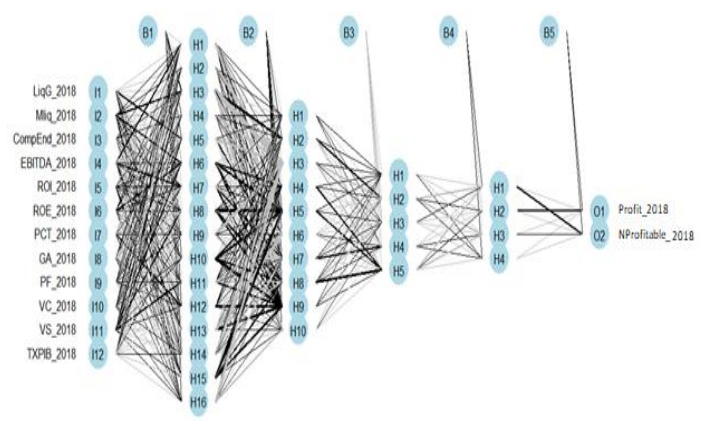

Figure 5. ANN structure estimated using Equation (38)

Source: Authors elaboration

The model variables are represented by I1, I2, I3 and so on, and are identified in the architecture by the variable's name, thus defining the correspondences, as shown in Figures 5, 6 and 7. The H1, H2, H3 and so on, represent each neuron, in each of the layers, which are identified by B1, B2, B3, B4 and B5, the latter being the output layer, which is calculated in the activation function to find the result.

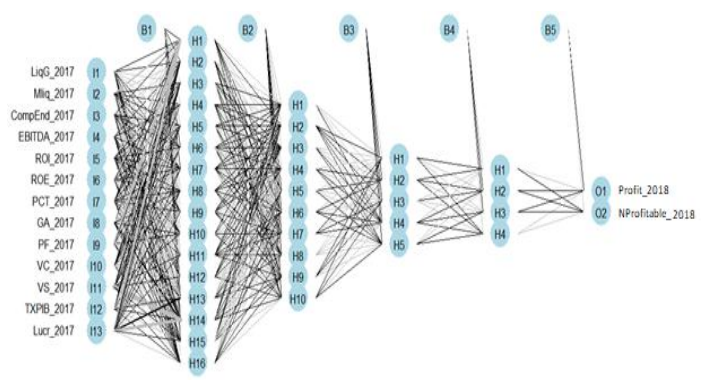

Figure 6. ANN structure estimated using Equation (39)

Source: Authors elaboration

As can be seen in Figures 5, 6 and 7, the ANN's architectures were built in the same way, so that it was possible to make a comparison between the models estimates. Thus, the ANN's were elaborated considering four hidden layers and an output layer; with respectively, 16, 10, 5 and 4 neurons, with two neurons in the last output layer, one of which represents the classification of profitable companies (Profit_2018) and the other, from injured companies (N Profitable_2018)

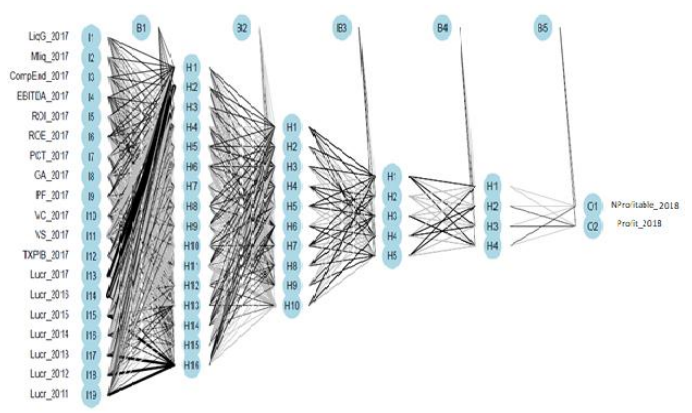

Figure 7. ANN Structure estimated using Equation (40)

Source: Authors elaboration 
For the generation of these networks, as well as for the estimation of discriminant functions, the data were separated into two random samples, with $50 \%$ of the observations in each one, with each sample being carried randomly. One of them was used to calculate the neural network and the discriminant analysis, the second sample was used to test the neural network and the discriminant analysis and to perform the companies' classification in this sample. More specifically, to test how many companies were classified correctly / incorrectly, thus identifying the percentage of correct estimates.

Table 2. ANN matrix adjustment

\begin{tabular}{|c|c|c|c|c|}
\hline \multirow{2}{*}{$\begin{array}{l}\text { Equatio } \\
\mathrm{n}\end{array}$} & \multirow[t]{2}{*}{ Classification } & \multicolumn{2}{|c|}{ Number of companies } & \multirow{2}{*}{ Accurancy (\%) } \\
\hline & & Profit & Loss & \\
\hline \multirow{2}{*}{ (38) } & Profit & 94 & 18 & \multirow{2}{*}{$83,80 \%$} \\
\hline & Loss & 5 & 25 & \\
\hline \multirow{2}{*}{ (39) } & Profit & 95 & 18 & \multirow{2}{*}{$84,51 \%$} \\
\hline & Loss & 4 & 25 & \\
\hline \multirow{2}{*}{ (40) } & Profit & 6 & 27 & \multirow{2}{*}{$15,49 \%$} \\
\hline & Loss & 93 & 16 & \\
\hline \multicolumn{2}{|l|}{ Total } & 99 & 43 & \\
\hline
\end{tabular}

Source: Authors elaboration

When estimating the ANN described by Equations (38), (39) and (40), according to Table 1, 94, 95 and 6 companies; respectively, were correctly classified as profitable and, respectively, 25, 25 and 16 companies were correctly classified in an injured situation. Thus, it appears that the ANN with the highest level of correctness was obtained with Equation (39), which presents the best level of forecasting companies situation, with $84.51 \%$ of companies correctly classified in situations of profit or loss. For example, of the 99 companies that were really profitable, according to Equation (39), 95 were classified as profitable while 4 of them were impaired; in addition, of the total of the 43 companies that were profitable, 25 of them were correctly classified, at a loss, while 18 were incorrectly defined as being in a profitable situation. Thus, the option was to present and discuss only the results of this equation.

The ANN structured in a contemporary way with Equation (38), presented a percentage of correct answers also above $83 \%$. This form of modeling was applied by Teixeira et al. (2013), using only the discriminant analysis and reached the level of accuracy of $82.8 \%$, in a sample composed of 255 companies listed in the financial market. This result can be corroborated by Chen and $\mathrm{Du}$ (2009), in which they obtained an accuracy of $82.14 \%$ with the use of neural networks relating the companies' situation. Azayite and Achchab (2018) reported a higher percentage, with $85 \%$ of accuracy correct in the classification of companies in solvents and non-solvents.

As, statistically, the ANN' s structured by Equations (38) and (39) present very similar results, the option was to analyze only the ANN with Equation (38), since, by the discriminant analysis, this specification was the one that presented the best fit, which allowed comparing results achieved with the two estimates.

Table 3. Estimate of variables importance in the ANN of Equation (38)

\begin{tabular}{clclcl}
\hline Variable & Statistic & Variable & Statistic & Variable & Statistic \\
\hline LiqG $_{2018}$ & $\mathbf{3 , 2 7}$ & $R O I_{2018}$ & $\mathbf{- 4 , 0 4}$ & $P F_{2018}$ & $\mathbf{2 2 , 0 1}$ \\
\hline Mliq $_{2018}$ & $\mathbf{- 4 , 1 9}$ & $R O E_{2018}$ & 1,08 & $V C_{2018}$ & 0,67 \\
\hline CompEnd $_{2018}$ & $\mathbf{4 , 0 6}$ & $P C T_{2018}$ & $-0,76$ & $V S_{2018}$ & 0,23 \\
\hline EBITD $A_{2018}$ & $-2,32$ & $G A_{2018}$ & $\mathbf{4 , 4 4}$ & $T X P I B_{2018}$ & 1,26 \\
\hline
\end{tabular}

Source: Authors elaboration 
Table 3 shows the importance of each variable in defining the ANN results in Equation (38), based on the method of Olden (2002). As demonstrated in the methodology, this importance is found by the sum of the multiplication of the input and output weight of each neuron in each layer, not having a unit of measurement. Thus, it is possible to verify that the economic variable $P F_{2018}$ has the highest degree of importance in ANN, with 22.01 among the variables analyzed to define the company's situation. Regarding the financial variables, those with the highest degree of importance are $G A_{2018}, M l i q_{2018}, R O I_{2018}$ and $L i q G_{2018}$, with 4.44, -4.19, -4.04 and 3.27, respectively. It is not possible to create a direct relationship between the ANN result with each variable, since, as the method of Olden and Jackson (2002) seeks only the magnitude of importance and not its meaning, this relationship between the variables is reported only through the synaptic weights (in statistical terms, parameters) of each neuron in each layer. It is important to note that synaptic weights are recalculated from layer to layer, with a reduction in the amount of neuron in each layer forward, according to the neural network learning.

It should be highlighted that, differently of what happens with $\mathrm{AD}$, where it is possible to extract unique estimates for each of the variables in order to constitute a discrimination function, in ANN it is not possible to extract a single parameter for each variable, as weights are generated by synaptic weight learning for each of the neurons in each layer, and thus the next layers of a network are calculated based on the neurons in the previous layers.

Table 4. Average of the ANN weights in Equation (38)

\begin{tabular}{clclcl}
\hline Variable & Estatistic & Variable & Estatistic & Variable & Estatistic \\
\hline LiqG $_{2018}$ & $\mathbf{- 0 , 5 3 1}$ & $R O I_{2018}$ & $\mathbf{- 0 , 6 4 6}$ & $P F_{2018}$ & $\mathbf{- 0 , 5 6 9}$ \\
\hline Mliq $_{2018}$ & 0,193 & $R O E_{2018}$ & 0,056 & $V C_{2018}$ & 0,160 \\
\hline CompEnd $_{2018}$ & $-0,330$ & $P C T_{2018}$ & $\mathbf{- 0 , 5 1 1}$ & $V S_{2018}$ & 0,143 \\
\hline EBITDA & & & \\
2018 & $-0,116$ & $G A_{2018}$ & $\mathbf{- 0 , 5 5 1}$ & $T X P I B_{2018}$ & $\mathbf{- 0 , 6 0 9}$ \\
\hline
\end{tabular}

Source: Authors Elaboration

Table 4 represents the average of the synaptic weights for each of the variables. Thus, it is possible to observe that the variables with the greatest effects on ANN are $L i q G_{2018}, R O I_{2018}, P C T_{2018}, G A_{2018}, P F_{2018}$ and $T X P I B_{2018}$, all with negative effects, except for $R O I_{2018}$.

All synaptic weights are available in the GitHub (Note 6) data repository, which can be accessed via web. These data can be used to reconstruct the network and discriminate against a new sample of companies, in addition to being used as a basis for future studies.

\subsection{Discriminant Functions Estimates}

Next, the results of the discriminant analysis performed with the same models used in ANN, Equations (38), (39) and (40) are presented. It begins with the test to identify whether the division between groups is statistically significant; then, the diagnoses of the most important variables in the discrimination of the groups are made and, finally, the discriminant functions are estimated.

Table 5. Statistical tests for the validation of discriminant functions

\begin{tabular}{llllll}
\hline Equation (38) & & Equation (39) & \multicolumn{3}{l}{ Equation(40) } \\
\hline Modified LR chi2 & 752 & Modified LR chi2 & 986.69 & Modified LR chi2 & 1742.414 \\
\hline Box F (91,67544.5) & 8,25 & Box F(91,67544.5) & 10.82 & Box F (210,66079.3) & 7.49 \\
\hline Box chi2(91) & 648,46 & Box chi2(91) & 850.50 & Box chi2(210) & 1438.86 \\
\hline Prob > F & 0,00 & Prob > F & 0,00 & Prob > F & 0,00 \\
\hline Prob > chi2 & 0,00 & Prob > chi2 & 0,00 & Prob > chi2 & 0,00 \\
\hline
\end{tabular}

Source: Authors Elaboration 
Table 5 summarizes the result of the M'Box test applied to Equations (38), (39) and (40). The test has as a null hypothesis the equality between the variance and covariance of group matrices. Thus, when the test is not statistically significant, the null hypothesis is not rejected, which means that the discriminant analysis is viable.

As the M'Box tests of the proposed models showed high statistical significance, less than $1 \%$ of significance; therefore, the null hypothesis is rejected in the three analyzed equations. Thus, matrices of variance and covariance of the groups, in each of these equations, are not the same, which violates one of the assumptions of the discriminant analysis. Thus, the estimated results, with Equations (38), (39) and (40), using the discriminant analysis method, do not become appropriate to classify the sampled companies as profitable and non-profitable.

However, even though there are statistical restrictions regarding the use of the discriminant analysis, it was decided to apply it, mainly, for the purpose of comparison with results achieved by the ANN models. Nevertheless, it is not possible to assume that the method has adequate accuracy for its application.

Table 6. Matrix adjustment of discriminant analysis

\begin{tabular}{|c|c|c|c|c|}
\hline \multirow[t]{2}{*}{ Equation } & \multirow[t]{2}{*}{ Situation } & \multicolumn{2}{|c|}{$\mathrm{N}^{\circ}$ of companies in } & \multirow{2}{*}{ Accuracy $(\%)$} \\
\hline & & Profit & Loss & \\
\hline \multirow{2}{*}{ (38) } & Profit & 92 & 16 & \multirow{2}{*}{$83,80 \%$} \\
\hline & Loss & 7 & 27 & \\
\hline \multirow{2}{*}{ (39) } & Profit & 79 & 10 & \multirow{2}{*}{$78,87 \%$} \\
\hline & Loss & 20 & 33 & \\
\hline \multirow{2}{*}{ (40) } & Profit & 82 & 11 & \multirow{2}{*}{$80,28 \%$} \\
\hline & Loss & 17 & 32 & \\
\hline
\end{tabular}

Source: Authors Elaboration

Table 6 shows the classification of companies and the number of correct answers and errors reported the application of the DA. In this perspective, the estimate of the highest level of correctness by the discriminant analysis occurred with Equation (38), with 83, 80\% of accuracy in the classification of the analyzed companies in a profitable or loss situation. For this reason, the option was made to focus only on its results. This level of accuracy was very close to the estimates of the discriminant function reported in Teixeira et al. (2013), who had an accuracy level of $82.8 \%$.

Table 7. Estimate of discriminant function - Equation (38)

\begin{tabular}{cccccl}
\hline Variable & Coeficient & Importance & Variable & Coeficient & Importance \\
\hline LiqG $_{2018}$ & $\mathbf{- 0 , 6 1 1}$ & $\mathbf{- 0 , 3 3 5}$ & $P C T_{2018}$ & $\mathbf{- 0 , 6 7 5}$ & $\mathbf{0 , 0 7 5}$ \\
\hline Mliq $_{2018}$ & $-0,306$ & $-0,281$ & $G A_{2018}$ & $-0,507$ & $-0,089$ \\
\hline CompEnd $_{2018}$ & 0,343 & $-0,010$ & $P F_{2018}$ & 0,164 & 0,013 \\
\hline EBITDA $A_{2018}$ & $-0,211$ & $-0,198$ & $V C_{2018}$ & $-0,116$ & $-0,017$ \\
\hline ROI $_{2018}$ & $\mathbf{- 0 , 5 8 9}$ & $\mathbf{- 0 , 3 0 4}$ & $V S_{2018}$ & $-0,203$ & $-0,095$ \\
\hline ROE $_{2018}$ & $\mathbf{- 1 , 0 8 8}$ & $\mathbf{- 0 , 4 0 7}$ & $T X P I B_{2018}$ & $\mathbf{0 , 3 6 5}$ & $\mathbf{0 , 0 8 5}$
\end{tabular}

Source: Authors Elaboration

Table 7 shows the estimates of the coefficients of Equation (38), as well as the degree of importance of each variable in this equation. Thus, the variable $R O E_{2018}$ has the highest degree of importance, with -0.407 of correlation with the discriminant function. If the effects of the other variables are isolated, and considering the coefficient of this variable of -1.088 , it is verified that the classification of the company in a profitable or loss situation suffers a negative effect from $R O E_{2018}$. There are two other relevant discriminating variables, $L_{i q G_{2018}}$ e a $R O I_{2018}$ with a 
correlation of -0.335 and -0.304 , respectively. The other variables listed in the table have little capacity to discriminate groups. Regarding the variable, even if it has a small importance in the discrimination of groups of 0.075 , the estimated coefficient of -0.675 indicates that it has the effect of discriminating against companies in a profitable/loss situation, because the greater the $P C T$, higher are the passive interest and consequently, lower profits.

Therefore, considering the problem of the present research, the ANN and AD models, more in tune with the outlined objectives, were structured by Equations (38) and (39), which presented a high degree of assertiveness in the prediction, about $84 \%$ of companies with profit or loss situation. This same percentage was obtained when estimating the discriminant function, structured by Equation (38). It is important to emphasize that one of the assumptions of the discriminant analysis was violated, the equality of the matrix of variance and covariance, which leads to caution in interpreting these results.

Comparing the results achieved with the ANN estimate of other studies, it was possible to note that the degree of assertiveness estimated in the present study is close to those obtained by Odom e Sharda (1990), Chen and Du (2009), Azayite and Achchab (2018), Teixeira et al. (2013) and Prado et al. (2020). The work of Odom and Sharda (1990) showed approximately $80 \%$ of accuracy in the three samples used. The percentage of correct answers by ANN obtained by Chen and Du (2009) was 82.14\%. In Azayite and Achchab (2018), the level of assertiveness of the model was $84.8 \%$, also with the use of ANN. Conversely, Teixeira et al. (2013) used the AD method, where the level of assertiveness in the classification of the sampled companies reached around 83\% without violating the hypothesis of equality of variance and covariance matrix of the two groups analyzed. Chung et al. (2008) also used ANN to estimate a model that could predict the financial situation of industrial companies in New Zealand, but presented an assertiveness percentage of $62 \%$, lower than the percentages estimated by the other authors mentioned above. Prado et al. (2020) estimated models for 100 companies in the commercial sector and reached $100 \%$ and $96.9 \%$ accuracy in both models which higher than those found in the literature. According to the authors, the tool has great relevance to evaluate important characteristics of financial statements.

Yildirim et al. (2011) and Björklund et al. (2017) sought to find the return of companies stills listed in the financial market. The first reached an assertiveness level of 95\% in forecasting the return of companies' stills, while the second obtained an estimate indicating that the use of ANN did not improve the portfolio optimization method.

Aydın et al. (2015) built an alert system to predict the possible situation of an economic-financial crisis using the ANN method with time series. According to the authors, the ANN estimates showed a high crisis prediction power.

In summary, mainly in relation to Chen and Du (2009), Azayite and Achchab (2018), Yildirim et al. (2011) and Prado et al. (2020), it is possible to verify that the ANN method has a high predictive power of companies on their economic and financial situation, thus constituting an important tool for credit risk analysis by financial institutions, managers companies and private investors.

It is necessary to point out that the application of the neural network with multiple layers and with a complex error propagation algorithm can have a high computational cost, especially when the volume of data enlarges. However, the ANN's estimated in the present study have an execution time of approximately 30 minutes for each equation, using a computer with an Intel Celeron Dual Core processor, 4GB of RAM, HD500GB and 5400RPM.

It is outstanding that the use of the ANN method has pros and cons. The main benefits are its high power to identify patterns and the possibility of using any type of variable, without presenting estimation errors; but, conversely, the interpretation of estimate variables, that is, the synaptic weights or parameters is not simple, as in $\mathrm{AD}$, not mentioning the absence of tests of variables significance. Thus, it is still necessary to develop more tools to more accurately assess its applicability.

Lastly, the results of this study may be useful to financial agents, shareholders and decision makers in open companies, with the purpose of reducing risk in forecasting companies situation, at the time of portfolios creation. Or even, considering the assertiveness of the neural network, it can become a very efficient support and alert tool in predicting the economic situation of the analyzed companies.

\section{Conclusion}

The present study constructed and estimated an artificial neural network (ANN) and a discriminating function to assess the economic and financial situation of Brazilian open companies, between 2011 and 2018. In both cases, we sought to structure the models in order to obtain the smallest possible error in the classification of the sampled companies, in a profitable or loss situation. 
Three models were built: the first sought to find contemporary relationships between the company's profit and loss situation from financial and economic information; the second estimated relations between the company's contemporary situation, profit or loss, with its most recent past, that is, the immediately preceding year; and the third model linked the contemporary situation of the company with all its past in the interval between 2011 and 2018 .

With the estimate performed, it was f reported that the best adjustments occurred with the ANN and the discriminant functions structured with Equations (38) and (39). For the ANN, these two equations showed approximately the same degree of assertiveness in classifying the companies' situation. However, the discriminant function was better structured with Equation (38).

For this reason, and for a parsimony assessment, results of Equation (38) were chosen. Thus, it was possible to verify that the financial variables: general liquidity, net margin, debt composition, return on investment, turnover of the asset, as well as the economic activity variable, industrial physical production, are relevant in the definition of the financial situation in which the company is. It is also worth mentioning that; although, the variable did not show a high degree of importance in the average ANN weights, the variable had a high effect to define the net result.

As the ANN presented a high predictive power, it can serve, empirically, to assist the decision making by financial market agents and company managers, so that it is possible to reduce as much as possible the loss of information in the economic-financial analysis of companies, as well as guaranteeing a low risk prediction, mainly for providing an aggregate view from a large number of variables. This allows to more precisely targeting the implementation of strategies to increase the competitiveness of the company in question in the market in which it operates.

Finally, the study aimed to contribute to the better understanding of important characteristics of the economic and financial information of Brazilian companies. According to the literature, the performance of the application of ANN showed better results than DA. In addition, the use of ANN is highly important for assessing the economic and financial situation of the companies, being able to evaluate characteristics what ir would not be possible with the descriptive analysis of the variables only.

It is worth highlighting, as a suggestion for future studies, the need to better understand the relationship between financial and economic information with the growth and survival capacity of companies, not only from the profit and financial situation, but also from the conduction company based on its organizational and institutional governance strategies. In addition, it is also suggested the application of time series neural network methods, thus considering the company's history, with the purpose of verifying whether the prediction capacity increases with the sampled companies.

\section{Reference}

Assaf Neto, A. (2018). Mercado Financeiro (14th ed.). São Paulo: Atlas.

Aydin, A. D., et al.. (2015). Prediction of financial crisis with artificial neural network: an empirical analysis on Turkey. International Journal of Financial Research, 6, 36-45.

Azayite, F. Z., \& Achchab, S. (2018). Financial early warning system model based on neural networks, PSO and SA algorithms. In H. Rodrigues (Ed.), EngOpt proceedings of the 6th.

Björklund, S. E., \& Uhlin, T. (2017). Artificial neural networks for financial time series prediction and portfolio optimization. Master Thesis, Science Department of Management and Engineering, Linköping University Sweden.

Retrieved

from https://www.soderbergpartners.se/globalassets/sv/om-oss/karriar/arets-finansuppsats/bjorklund-s.--uhlin-t.-artifi cial-neural-networks-for-financial-time-series-prediction-and-portfolio-optimization.pdf

Braga, A. P., Carvalho, A. P. L., \& Ludermir, T. B. (2000). Redes Neurais Artificiais: Teoria e Aplicações (2nd ed.). Rio de Janeiro: LTC Editora.

Brasil Bolsa Balcão-B3. (2019). Retrieved December 5, 2019, from http://www.b3.com.br/pt_br/

Chen, W. E., \& Du, Y. (2017). Using neural networks and data mining techniques for the financial distress prediction model. Expert Systems with Applications, 36, 4075-4086. Retrieved January 8, 2020, from http://citeseerx.ist.psu.edu/viewdoc/download?doi=10.1.1.452.4753\&rep=rep1\&type=pdf

Chung, K., et al.. (2008). Insolvency prediction model using multivariate discriminant analysis and artificial neural network for the finance industry in New Zealand. International Journal of Business and Management, 39(1), 19-28.

Doing Business. (2018). Medindo a regulamentação do ambiente de negócios - Ranking Facilidade em Fazer Negócios. The World Bank Group. Retrieved January 1, 2019, from https://portugues.doingbusiness.org/

Gitman, L. J. (2010). Princípios da administração financeira (12th ed.). São Paulo: Pearson Prentice Hall. 
Guo, Z., \& Luo, Y. (2017). Credit constraint exports in countries with different degrees of contract enforcement. Business and Economic Research, 7(1), 227-241.

Hair, Jr. J. F., et al.. (2009). Análise Multivariada de Dados (6th ed.). Porto Alegre: Bookman.

Haykin, S. (2001). Redes neurais: princípios e prática (2nd ed.). Porto Alegre: Bookman.

IBGE, Instituto Brasileiro de Geografia e Estatística. (2019). Pesquisas Industrial, de serviço e comercio. Retrieved December 2, 2019, from https://www.ibge.gov.br/

InteANNtional Conference on Engineering Optimization, \& EngOpt. (2018). Financial Early Warning System Model Based on Neural Networks, PSO and SA Algorithms. EngOpt 2018 Proceedings of the 6th International Conference on Engineering Optimization (pp. 970-982). Retrieved October 22, 2019, from https://link.springer.com/chapter/10.1007/978-3-319-97773-7_84

Johnson, R. A., \& Wichern, D. W. (2007). Applies multivariate statistical analysis (6th ed.). Upper Saddle River, New Jersey: Pearson, Prentice Hall.

Manly, B. F. J., \& Navarro, A. J. (2017). A multivariate statistical methods: a primer (2th ed.). Boca Raton: CRC Press.

Márion, J. C. (2012). Análise das demonstrações contábeis: contabilidade empresarial (7th ed.). São Paulo: Atlas.

Matarazzo, D. C. (2010). Análise financeira de balanços: abordagem gerencial (7th ed.). São Paulo: Atlas.

Mingoti, S. A. (2017). Análise de dados através de métodos de estatística multivariada: uma abordagem aplicada. Belo Horizonte: Editora UFMG.

Odom, M. D., \& Sharda, R. (1990). A neural network model for bankruptcy prediction. IJCNN International Joint Conference on Neural Networks (Vol. 2, pp. 163-168). San Diego, CA, USA, 1990.

Olden, J. D., \& Jackson, D. A. (2002). Illuminating the "black box": a randomization approach for understanding variable contributions in artificial neural networks. Ecological Modelling, 154, 135-150.

Prado, J. W., et al.. (2020). Previsão Da Insolvência Empresarial Utilizando Redes Neurais Artificiais, Gestão e Desenvolvimento. Novo Hamburgo, 17(2).

Riedmiller, M., \& Braun, H. A. (1993). Direct Adaptive Method for Faster Backpropagation Learning: The RPROP Algorithm. Proceedings of the IEEE International Conference on Neural Networks (pp. 586-591). San Francisco, 28 March-1. Retrieved December 22, 2019, from https://ieeexplore.ieee.org/document/298623/

Rumelhart, D., et al.. (1986). Learning representations by back-propagating errors. Nature, 323, 533-536. Retrieved from https://www.nature.com/articles/323533a0

Teixeira, S. A., et al.. (2013). Análise discriminante como preditiva de dificuldades financeiras em empresas brasileiras do mercado acionário. Revista Catarinense da Ciência Contábil CRCSC, 12(36), 38-52.

Yildirim, I., et al.. (2011). Prediction of the financial return of the paper sector with artificial neural networks. BioResourses, 6(4), 4076-4091. Retrieved August 15, 2019, from https://ojs.cnr.ncsu.edu/index.php/BioRes/article/view/BioRes_06_4_27_Yildirim_OA_Predict_Financial_Retu rn_Paper_Sector/1159

\section{Notes}

Note 1. The content of this section is based on Haykin (2001), the exceptions are referenced.

Note 2. According to Haykin (2001), the threshold function, also known as the Heaviside function, will assume a value of 1 if it is positive, otherwise, it will assume a value of 0 , thus being defined as $y k=\{1, \mathrm{se} v \mathrm{vk} \geq 00$, se $\mathrm{vk}<0$.

Note 3. Discriminant functions estimates were performed using the Stata ${ }^{\circledR} 15$ program.

Note 4 . The reader can find details of the test in the indicated reference.

Note 5. See the test specification in Manly and Navarro (2017).

Note 6. Repository link on GitHub: https://github.com/VargasEmanuel/ANN-AD-FinancialSA.

\section{Copyrights}

Copyright for this article is retained by the author(s), with first publication rights granted to the journal.

This is an open-access article distributed under the terms and conditions of the Creative Commons Attribution license (http://creativecommons.org/licenses/by/4.0/). 